\title{
World Journal of Comparison between
Pediatric Surgery hepaticojejunostomy and hepaticoduodenostomy after excision of choledochal cyst in children: a cohort study
}

\section{Johann Paulo Suico Guzman, Leandro L Resurreccion III, Marcus Lester R Suntay, Renato G Bernaldez}

To cite: Guzman JPS, Resurreccion III LL, Suntay MLR, et al. Comparison between hepaticojejunostomy and hepaticoduodenostomy after excision of choledochal cyst in children: a cohort study. World Jnl Ped Surgery 2019;2:e000029. doi:10.1136/wjps-2018-000029

Received 23 December 2018 Revised 22 January 2019 Accepted 22 January 2019
Check for updates

Cㄱ Author(s) (or their employer(s)) 2019. Re-use permitted under CC BY-NC. No commercial re-use. See rights and permissions. Published by BMJ.

Pediatric Surgery, Philippine Children's Medical Center, Quezon City, Philippines

Correspondence to Dr Johann Paulo Suico Guzman; yooohannn@yahoo.com

\section{ABSTRACT}

Objective Hepaticojejunostomy (HJ) and hepaticoduodenostomy (HD) are commonly used biliary reconstruction techniques after choledochal cyst excision. $\mathrm{HD}$ has been suggested to be a more physiologic alternative during reconstruction. The objective of this study is to compare operative time, hospital stay, morbidity (leak, cholangitis, ileus, and obstruction), and mortality between $\mathrm{HJ}$ and $\mathrm{HD}$ after cyst excision.

Methods This is a 14-year retrospective cohort study of pediatric patients ( $\leq 18$ years old) who underwent choledochal cyst excision and subsequent biliary reconstruction at the Philippine Children's Medical Center. Data were taken from inpatient charts, operative technique, OPD logbook, readmission, and OPD charts.

Results There were 122 patients: $56 \% \mathrm{HD}$ and $44 \% \mathrm{HJ}$. Majority were female (72\%), with 1:2.6 male to female ratio. The average age was 36.1 months, with a mean follow-up of 32.8 months (range 6 months-14 years). The most common cyst was type I (87\%). Operative time was longer for $\mathrm{HJ}$ compared with HD (321.3 vs $203.6 \mathrm{~min} ; \mathrm{p}=0.000$ ). Hospital stay was longer with $\mathrm{HJ}$ compared with HD (7.7 vs 6.8 days; $p=0.002$ ). Mortality rate was low at $1.6 \%$ while morbidity was at $13.9 \%$ in both groups. Although morbidity was higher among those who underwent $\mathrm{HD}$, there was no significant difference between the two procedures. Anastomotic leak (4\%) and cholangitis $(7.4 \%)$ were observed in $\mathrm{HD}$, and ileus $(7.4 \%)$ was observed in the $\mathrm{HJ}$ group.

Conclusions In our series, HD provided less operative time and hospital stay than with HJ. We did not observe bile gastritis after HD as compared with others. It is suggested that longer follow-up is needed to confirm such findings.

\section{INTRODUCTION}

The reconstruction for biliary enteric continuity after choledochal cyst resection favors the use of a Roux-en-Y anastomosis because it offers lesser complications of cholangitis and anastomotic leaks. ${ }^{1}$ The treatment of choledochal cyst commonly involves excision of the cyst, but the biliary enteric continuity can be achieved with different reconstruction techniques. ${ }^{2}$ Some surgeons prefer to use hepaticojejunostomy (HJ) anastomosis with an Roux-en-Y limb, while others use hepaticoduodenostomy (HD) reconstruction. Advocates of using $\mathrm{HJ}$ anastomosis state that it has lesser complications of bile leak afforded by less tension on the suture line by the Roux limb, and it affords enteric diversion away from the biliary tree, thus preventing cholangitis postoperatively. ${ }^{3}$ The advantages of HD include faster operative time because it only has one anastomosis compared with three in a jejunal reconstruction, and faster recovery of bowel function due to less bowel manipulation. ${ }^{4}$ It is thought that using the duodenum as conduit for anastomosis entails greater incidence of reflux, leading to higher incidence of postoperative cholangitis, anastomotic stricture, and rarely carcinoma development. ${ }^{5}$

The incidence of cholangitis after biliary reconstruction is largely attributed to the ascending passage of enteric bacteria to the biliary tract. A Roux-en-Y HJ uses a defunctionalized long limb that affords enteric diversion from the biliary tree. A duodenal conduit for HD theoretically has a higher incidence of cholangitis because of the direct access of enteric bacteria from the duodenum to the biliary tree. Hsieh et at provided this explanation of ascending cholangitis in rat models using Escherichia coli strains injected by gel electrophoresis in the biliary enteric conduits.

Using the duodenum in the biliary reconstruction has some advantages of lesser operative times and lesser incidence of leaks because of the single anastomosis. The requirements for a safe HD is that the duodenum should 
be sufficiently mobilized to be able to reach the common bile duct stump for a tension-free anastomosis. If there is tension in the anastomosis, it is contraindicated and it should be converted to $\mathrm{HJ}^{7}$

In a 15-year review of Silva-Baez et $a l^{2}$ last 2015 in patients who underwent $\mathrm{HJ}$ anastomosis, they have found a $25 \%$ complication rate compared with those who had HD anastomosis, which had a rate of $16.6 \%$. Complications include cholangitis, leak and postoperative reflux. In their series, they have found no mortalities, and they support the use of the duodenum as a safer alternative and offer lesser complications to using Roux limb reconstruction. ${ }^{2}$

\section{METHODS}

Research design and description of the study procedure

This study is a 15-year retrospective cohort study of patients 18 years old and below who were diagnosed with choledochal cyst and who underwent cyst excision and subsequent biliary reconstruction at the Division of Pediatric Surgery, Philippine Children's Medical Center. The study period included patients from 2002 up to 2016. There were two groups of patients: one group included those who had $\mathrm{HJ}$ and the other group those who underwent HD. Patients' operative records were recovered from the Division of Pediatric Surgery's monthly operative census and from the hospital's medical records. A total of 122 patients were included in the study. The size of the common bile duct during ultrasound in all of these patients ranges from $1 \mathrm{~cm}$ to $9 \mathrm{~cm}$. The type of reconstruction depended on the following factors: biliary anatomy, the surgeon's technical familiarity of the procedure and the patient's preoperative status. The type of biliary reconstruction was primarily decided by the surgeon's preference; there was no randomization done. There were three cases done laparoscopically and the rest were done with open surgery.

\section{Operative techniques}

After standard cyst excision in open cases, during HD reconstruction the duodenum is mobilized by Kocherization. The remaining proximal common hepatic duct after cyst excision is flushed to clear out debris and is anastomosed $2 \mathrm{~cm}$ distal to the pylorus using interrupted absorbable 4-0 sutures. In cases where $\mathrm{HJ}$ was used, the Roux limb is created by transecting the jejunum $15 \mathrm{~cm}$ distal to the ligament of Treitz and brought up to the hilum $40 \mathrm{~cm}$ in length. The jejujejunostomy is done, completed with a single-layer anastomosis with 4-0 absorbable sutures to the end of the proximal jejunum to the side of the Roux limb, making sure that the Roux limb brought up is $40 \mathrm{~cm}$. The biliary enteric continuity is completed with an end-to-side fashion $1 \mathrm{~cm}$ proximal to the end of the limb.

In the select three cases that were done laparoscopically, the size of the CBD measured by ultrasound ranged from $1 \mathrm{~cm}$ to $2 \mathrm{~cm}$, which was relatively smaller. The procedure was carried out with four ports: $10 \mathrm{~mm}$ umbilical port and three $3.5 \mathrm{~mm}$ working ports at the right flank, left flank and the left subcostal area. This technique is similar to the one performed by Liem et $a l^{89}$ After ligation of the cystic artery and duct, the proximal gall bladder was suspended transabdominally to aid the exposure of the hilum. The cyst is dissected circumferentially using cautery and transacted near the junction of the cystic duct and the common hepatic duct. The distal cyst was ligated with clips as it tapers near the junction of the pancreatic duct. In all laparoscopic cases, HD was used and was performed similarly as described earlier in open surgery.

These data were recorded in the preoperative logbooks and they were used in the data collection. Data on follow-up of patients were based on the out-patient department (OPD) census logbooks, readmission in patient charts and OPD charts.

The inclusion criteria were all pediatric patients (younger than 18 years old) who underwent excision of choledochal cyst with subsequent biliary reconstruction. The exclusion criteria were patients who underwent diversion procedures for choledochal cysts, patients who had intrahepatic chloledochal cysts (type V) where complete excision is not possible and patients who had biliary reconstruction for malignant reasons.

All patients who underwent surgery were followed up at regular intervals. The Pediatric Gastroenterology Section, along with the Pediatric Surgery Service, saw patients postoperatively. Patients' follow-up schedule at OPD Surgery entails them to go to the OPD 2 weeks after surgery and monthly thereafter. The OPD records of these patients were then used in the data collection; their clinical status, development of new symptoms, morbidity incurred and length of follow-up were recorded. For those patients who were lost to follow-up, they were called through the telephone number provided on the data identification sheet in the patient's chart to assure compliance to follow-up. During the phone interview, patients were asked to follow up at the OPD Surgery. The last date of follow-up was based on the last follow-up at the OPD. If the patient was readmitted, data from the readmission charts were taken and recorded.

Summary statistics were presented in the tables as median quantitative variables and as $\mathrm{n}(\%)$ for categorical outcome measures. Checks for homogeneity of sample population and normality assumption were performed. Mann-Whitney $\mathrm{U}$ test was used to compare averages. $\chi^{2}$ test was used to compare proportions. Statistical significance was based on $p$ value $\leq 0.05$.

\section{RESULTS}

There were 122 patients who underwent choledochal cyst excision and eventual biliary reconstruction, $56 \%$ HD and $44 \%$ HJ. Three patients who had HD underwent laparoscopic excision and reconstruction, whereas the rest were done in open procedures. Majority were female 
Table 1 Demographic characteristics and clinical presentation of 122 patients who underwent excision of choledochal cyst and subsequent biliary reconstruction at the Philippine Children's Medical Center from 2003 to 2016

\begin{tabular}{|c|c|c|c|c|c|}
\hline & $\begin{array}{l}\text { All patients } \\
\text { n (\%) } \\
122(100)\end{array}$ & $\begin{array}{l}\text { Hepaticoduodenostomy } \\
n(\%) \\
68(56)\end{array}$ & $\begin{array}{l}\text { Hepaticojejunostomy } \\
\text { n (\%) } \\
54(44)\end{array}$ & $P$ value & $\begin{array}{l}\text { Mean difference } \\
\pm \text { SE }(95 \% \mathrm{Cl})\end{array}$ \\
\hline Age (mean in months) & 36.1 & 40.4 & 31.4 & 0.204 & $\begin{array}{l}1.289 \pm 1.220 \\
(0.869 \text { to } 1.913)\end{array}$ \\
\hline \multicolumn{6}{|l|}{ Gender, n (\%) } \\
\hline Male & $34(27.9)$ & $19(27.9)$ & $15(27.8)$ & 0.984 & Not applicable \\
\hline Female & $88(72.1)$ & $49(72.1)$ & $39(72.2)$ & & \\
\hline \multicolumn{6}{|l|}{ Type of cyst, n (\%) } \\
\hline 1 & $106(86.9)$ & $57(83.8)$ & $49(90.7)$ & 0.268 & Not applicable \\
\hline II & $10(8.2)$ & $8(11.8)$ & $2(3.7)$ & & \\
\hline IV & $6(4.9)$ & $3(4.4)$ & $3(5.6)$ & & \\
\hline Operative times in min (mean) & 249.2 & 203.6 & 321.3 & $0.000^{\star}$ & $\begin{array}{l}0.634 \pm 1.058 \\
(0.566 \text { to } 0.708)\end{array}$ \\
\hline Hospital stay in days (mean) & 7.1 & 6.8 & 7.7 & $0.002^{*}$ & $\begin{array}{l}-0.881 \pm 0.284 \\
(-1.444 \text { to } 0.319)\end{array}$ \\
\hline Duration of follow-up in months (mean) & 32.8 & 36.2 & 28.6 & 0.263 & $\begin{array}{l}7.619 \pm 6.775 \\
(-5.799 \text { to } 21.038)\end{array}$ \\
\hline
\end{tabular}

${ }^{*} t$-Test significant at the $5 \%$ level.

(72\%), with a 1:2.6 male to female ratio. The average age of the cohort was 36.1 months old; older patients underwent HD ( $\mathrm{p}=0.244)$. The most common cyst was type I $(87 \%)$. The characteristics of patients in both groups were homogeneous with respect to age, gender, and type of cyst (table 1). The average operative time was 249.2 min, longer for $\mathrm{HJ}$ compared with patients who underwent HD (321.3 vs $203.6 \mathrm{~min} ; \mathrm{p}=0.000$ ). Patients stayed in the hospital for an average of 7.1 days \pm 1.5 (SD), longer for those who underwent HJ (7.7 vs 6.8 days; $\mathrm{p}=0.002$ ). The mean follow-up in the cohort of patients was 32.8 months (range 6 months-14 years).

Mortality rate was low at $1.6 \%$, while morbidity was at $13.9 \%$. Although the rate was higher among those who underwent $\mathrm{HD}$, there was no significant difference between the two procedures (table 2).

Table 3 enumerates the different causes of mortality and morbidity in both groups of reconstruction. In the HD group, two patients died. One patient died of sepsis secondary to anastomotic leak. In this patient in whom a leak was considered, the presentation was sepsis, with signs of peritonitis and pneumoperitoneum. The other mortality was in a patient who presented with cholangitis. In this patient, the diagnosis was made and the patient underwent an emergency revision of the reconstruction, but subsequently succumbed to sepsis postoperatively.
In both groups of reconstruction, anastomotic leak was diagnosed with bilious drainage from the drain site, and in all of these cases, except one, they were successfully managed conservatively. Conservative management included delaying enteral feeding, institution of antibiotics, and delayed removal of the drain. There was one case of anastomotic leak in the HD group in which there was a revision of the reconstruction using a Roux limb. This patient presented with signs of peritonitis, fever and continued bilious drainage output.

There was no patient who had cholangitis during follow-up in the HJ group, whereas there were five cases of cholangitis in the HD group. In all of these cases, they were also successfully managed conservatively with antibiotic treatment.

There was one case of pancreatitis in the HD group, who presented postoperatively with abdominal pain and elevated pancreatic enzymes. In this patient, there was resolution of pancreatitis and was discharged unremarkable.

There was one case of intestinal obstruction in the $\mathrm{HJ}$ group in need of re-exploration. During exploration, the cause of the obstruction was an internal hernia which was secondary to the mesenteric defect during the creation of the Roux limb.

Table 2 Mortality and morbidity of 122 patients who underwent excision of choledochal cyst and subsequent biliary reconstruction at the Philippine Children's Medical Center from 2003 up to 2016

\begin{tabular}{|c|c|c|c|c|}
\hline & All patients & Hepaticoduodenostomy & Hepaticojejunostomy & \\
\hline & $\begin{array}{l}n(\%) \\
122(100)\end{array}$ & $\begin{array}{l}n(\%) \\
68(56)\end{array}$ & $\begin{array}{l}n(\%) \\
54(44)\end{array}$ & $P$ value \\
\hline Mortality & $2(1.6)$ & $2(2.9)$ & 0 & 0.234 \\
\hline Morbidity & $17(13.9)$ & $10(14.7)$ & $7(13.0)$ & 0.782 \\
\hline
\end{tabular}


Table 3 Different causes of mortality and morbidity of 122 patients who underwent excision of choledochal cyst and subsequent biliary reconstruction at the Philippine Children's Medical Center from 2003 to 2016

\begin{tabular}{|c|c|c|}
\hline & Hepaticoduodenostomy & Hepaticojejunostomy \\
\hline & $\begin{array}{l}n(\%) \\
68(56)\end{array}$ & $\begin{array}{l}n(\%) \\
54(44)\end{array}$ \\
\hline \multicolumn{3}{|l|}{ Mortality } \\
\hline Cholangitis & $1(1.47)$ & \\
\hline Anastomotic leak & $1(1.47)$ & \\
\hline \multicolumn{3}{|l|}{ Morbidity } \\
\hline Anastomotic leak & $3(4.4)$ & $3(4.4)$ \\
\hline Cholangitis & $5(7.4)$ & \\
\hline Pancreatitis & $1(1.5)$ & \\
\hline Intestinal obstruction & & $1(1.9)$ \\
\hline Upper gastrointestinal & $1(1.5)$ & \\
\hline \multicolumn{3}{|l|}{ Bleed } \\
\hline lleus & $1(1.5)$ & $4(7.4)$ \\
\hline
\end{tabular}

There was one case of upper gastrointestinal bleed in the HD group. The patient presented during follow-up with hematochezia necessitating endoscopy. During endoscopy, they noted variceal bleeding and bleeding gastritis with no note bile reflux in the stomach. Conservative management included placing the patient on proton pump inhibitors and rubber band ligation.

Ileus was more common in the $\mathrm{HJ}$ group as the reconstruction entails more bowel manipulation during the reconstruction. In all of these patients, they presented with delayed return of bowel function, abdominal distension, and radiologic findings of ileus.

\section{DISCUSSION}

The use of duodenum on enteric continuity is associated with lesser operative times and shorter hospital stays compared with using a Roux limb for reconstruction. ${ }^{510}$ In this study there is a statistical difference between the HD group and the HJ group in both operative time (203.6 min vs $321.3 \mathrm{~min}$ ) and hospital stay (6.8 days vs 7.7 days). This may be due to the fact that single anastomosis was involved in the first group compared with the multiple anastomoses in the reconstruction using the Roux limb. Although morbidity and mortality rates are not statistically significant in both groups, there are specific complications that are unique in each type of reconstruction. Although the two deaths in the HD group did not reach statistical significance, it is still of clinical importance.

Our Japanese colleagues reported a 33\% (12 cases) incidence of endoscopically proven bilious gastritis after HD. ${ }^{1}$ Some authors reported that all cases in their series after HD (eight cases) have mild to moderate gastric mucosal erosion and reflux of bile through the pyloric ring after routine endoscopic examination on all of their cases after HD. ${ }^{11}$ In our institution, we only do endoscopy in symptomatic cases after HD where we suspect gastritis or bile reflux. In our series, we did only three endoscopy cases from the HD group and none from the HJ group. In the three cases, ulcerations were noted, which were all secondary to Helicobacter pylori with no evidence of bile reflux. This finding is in contrast to our Japanese counterparts. We have not adopted a policy of routine endoscopy in all cases after HD. It can be argued that most endoscopically proven bile reflux gastritis can be minimally asymptomatic and we have not found routine endoscopy of value in our setting. Liem $e t a l^{8}$ also reported a $14.3 \%$ incidence of bilious gastritis in their series performed laparoscopically.

In our series, it is notable that, although it did not reach statistical significance, there is a higher frequency of anastomotic leaks $(\mathrm{p}=0.781)$ in the HD group. Various studies state that the limitation of the HD is that there may be tension during the procedure when using the duodenum in the reconstruction, making the use of Roux limb suitable for reconstruction. ${ }^{5}{ }^{12}$ In our series, the leaks observed in HD were successfully managed conservatively, indicating leaks occurring on these patients are minor. But caution should be exercised when signs of peritonitis and hemodynamic instability develop because these warrant exploration and revision of the anastomosis. Ultimately, intraoperative findings will dictate surgical judgment on which type of reconstruction to use; if too much tension is encountered in the procedure, a Roux limb is a surgically sound option during such cases.

One theoretical advantage of using a Roux limb during the reconstruction is the lower incidence of reflux of enteric stream to the biliary tree, lowering the chance of cholangitis postoperatively. This was also observed in this study; none of the patients who underwent $\mathrm{HJ}$ developed cholangitis compared with those who underwent HD. Cholangitis can occur in these patients if stricture formation occurs. According to Dimou et al, ${ }^{13}$ in a group of 3374 patients, the cumulative incidence of stricture was $12.5 \%$ at 2 years, and the mean time to stricture diagnosis was $16.8 \pm 21.6$ months (median=8.5 months). In our series, patients developed signs of cholangitis within 2 years after surgery. The time needed for stricture formation supports the follow-up among patients who underwent HD for the development of cholangitis later on. Surgeons argue that $\mathrm{HJ}$ provides a more durable reconstruction by following the recommendations suggested by Yamataka $e t$ al. ${ }^{14}$ These are (1) end-to-end anastomosis if possible; (2) if end-to-side anastomosis is unavoidable, the common hepatic duct should be anastomosed as close as possible to the closed end of the blind pouch; (3) careful selection of the vascular supply to the Roux jejunal limb; and (4) the length of the Roux limb should not be predetermined, but individualized. ${ }^{14}$ In our series, we observed an intestinal obstruction which was secondary to mesenteric defect during the reconstruction of the Roux limb. It may be also reasonable to be meticulous and repair for iatrogenic mesenteric defects created during the reconstruction.

As noted in this study, there was higher incidence of cholangitis in the HD group compared with the 
$\mathrm{HJ}$ group, but it did not reach statistical significance $(p=0.115)$. Cholangitis is theorized to occur from bile stasis and reflux of duodenal content into the terminal common bile duct with bacterial overgrowth, with subsequent relative obstruction of the biliary tree. Other authors argue that cholangitis in HD could be addressed by endoscopic maneuvers to relieve the obstruction, thus eliminating the fear of subsequent development of this complication. ${ }^{15}$ This in fact may be considered as an advantage of HD because of the various therapeutic endoscopic options especially in the management of cholangitis. Endoscopy can address anastomotic stricture formation in these patients. But in our setting there is limited availability of a side-viewing endoscope for pediatric patients, which is needed for endoscopic management when faced with this complication; thus, this must be considered in the treatment options. But our results show that in those who developed cholangitis, majority of the patients responded to conservative treatment of antibiotics, implying that the reflux enteric content into the biliary tree is transient.

It is obvious that we still perform most of our cases as open surgeries, the reason probably is that most of the cases that we see are those with large cyst sizes, with some cyst as big as $9 \mathrm{~cm}$. In most of the laparoscopic cases being reported, their series reported cyst size range of only $1-1.7 \mathrm{~cm} .{ }^{89}$ Arguably, we probably see a different sample of population from our part of the world in terms of cyst size and patient characteristics in contrast to those performed by our colleagues, but in select cases we offer the minimally invasive approach when we see smaller cyst sizes manageable for laparoscopy.

\section{CONCLUSION}

In our series, the use of the duodenum in the reconstruction after cyst excision shows shorter operative times and hospital stays with similar morbidity and mortality rates compared with using a Roux limb reconstruction, similar to those reported in the literature. We have not observed bile gastritis in our series. Due to the retrospective nature of this study and the relatively short mean time of follow-up ( 2.7 years), it is recommended to have a longer observation time. The use of routine endoscopy in all cases with HD could still be debatable, and comparison between routine and selective endoscopy could be an area of active study.

Contributors JPSG: planning of the study, drafting of the proposal, data collection, writing of the manuscript, editing and revision of the manuscript. LLR: drafting of the proposal, editing of the manuscript. MLRS: editing and revision of the manuscript. RGB: designing the conceptual framework, draft proposal.

Funding The authors have not declared a specific grant for this research from any funding agency in the public, commercial or not-for-profit sectors.

Competing interests None declared.

Patient consent for publication Not required.

Ethics approval This study was approved by the ethics review board of our institution.

Provenance and peer review Not commissioned; externally peer reviewed.

Open access This is an open access article distributed in accordance with the Creative Commons Attribution Non Commercial (CC BY-NC 4.0) license, which permits others to distribute, remix, adapt, build upon this work non-commercially, and license their derivative works on different terms, provided the original work is properly cited, appropriate credit is given, any changes made indicated, and the use is non-commercial. See: http://creativecommons.org/licenses/by-nc/4.0

\section{REFERENCES}

1. Shimotakahara A, Yamataka A, Yanai T, et al. Roux-en-Y hepaticojejunostomy or hepaticoduodenostomy for biliary reconstruction during the surgical treatment of choledochal cyst: which is better? Pediatr Surg Int 2005;21:5-7.

2. Silva-Baez H, Coello-Ramírez $\mathrm{P}$, Ixtabalán-Escalante EM, et al. Treatment of choledochal cyst in a pediatric population. A single institution experience of 15-years. Case series. Ann Med Surg 2016;5:81-5.

3. Gardikis S, Antypas S, Kambouri K, et al. The Roux-en-Y procedure in congenital hepato-biliary disorders. Rom J Gastroenterol 2005;14:135-40.

4. Santore MT, Behar BJ, Blinman TA, et al. Hepaticoduodenostomy vs hepaticojejunostomy for reconstruction after resection of choledochal cyst. J Pediatr Surg 2011;46:209-13.

5. Narayanan SK, Chen Y, Narasimhan KL, et al. Hepaticoduodenostomy versus hepaticojejunostomy after resection of choledochal cyst: a systematic review and meta-analysis. $J$ Pediatr Surg 2013;48:2336-42.

6. Hsieh CS, Huang L-T, Huang CC, et al. Bacteria ascend to liver from the bilioenteric conduit after choledochojejunostomy in the cholestatic rat. Pediatr Surg Int 2003;19:699-702.

7. Serber J, Stranzinger E, Geiger JD, et al. Association of gastroschisis and choledochal cyst. J Pediatr Surg 2009;44:e23-6.

8. Liem NT, Dung leA, Son TN. Laparoscopic complete cyst excision and hepaticoduodenostomy for choledochal cyst: early results in 74 cases. J Laparoendosc Adv Surg Tech A 2009;19 Suppl 1:s87-90.

9. Liem NT, Pham HD, Dung leA, et al. Early and intermediate outcomes of laparoscopic surgery for choledochal cysts with 400 patients. J Laparoendosc Adv Surg Tech A 2012;22:599-603.

10. Shah O, Shah P, Zargar S. Hepaticocholecystoduodenostomy compared with Roux-en-Y choledochojejunostomy for decompression of the biliary tract. Ann Saudi Med 2009;29.

11. Takada K, Hamada Y, Watanabe K, et al. Duodenogastric reflux following biliary reconstruction after excision of choledochal cyst. Pediatr Surg Int 2005;21:1-4.

12. Hirano S, Tanaka E, Tsuchikawa T, et al. Techniques of biliary reconstruction following bile duct resection (with video). $J$ Hepatobiliary Pancreat Sci 2012;19:203-9.

13. Dimou FM, Adhikari D, Mehta HB, et al. Incidence of hepaticojejunostomy stricture after hepaticojejunostomy. Surgery 2016;160:691-8.

14. Yamataka A, Kobayashi $H$, Shimotakahara A, et al. Recommendations for preventing complications related to Roux-en-Y hepatico-jejunostomy performed during excision of choledochal cyst in children. J Pediatr Surg 2003;38:1830-2.

15. Leppard WM, Shary TM, Adams DB, et al. Choledochoduodenostomy: is it really so bad? J Gastrointest Surg 2011;15:754-7. 